\title{
Open Repair of an Incidentally Diagnosed Hepatic Artery Aneurysm
}

\author{
Rodrigues Roger ${ }^{*}$, Vilaça Luis² ${ }^{2}$ Oliveira João ${ }^{2}$, Ferreira Ana², Vieira Mário² and Assunção António² \\ ${ }^{1}$ Department of Angiology and Vascular Surgery, University Hospital of Coimbra, Portugal
}

${ }^{2}$ Department of Angiology and Vascular Surgery, Hospital of Braga, Portugal

Received: May 10, 2018; Published: May 25, 2018

*Corresponding author: Roger Rodrigues, Department of Angiology and Vascular Surgery, University Hospital of Coimbra, Portugal, Tel: +351918400967; Email: roger.cc@hotmail.com

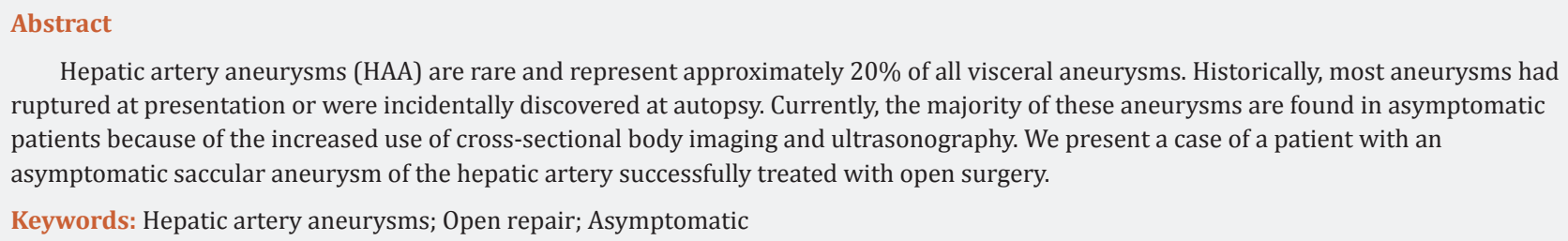

Hepatic artery aneurysms (HAA) are rare and represent approximately $20 \%$ of all visceral aneurysms. Historically, most aneurysms had ruptured at presentation or were incidentally discovered at autopsy. Currently, the majority of these aneurysms are found in asymptomatic patients because of the increased use of cross-sectional body imaging and ultrasonography. We present a case of a patient with an asymptomatic saccular aneurysm of the hepatic artery successfully treated with open surgery.

Keywords: Hepatic artery aneurysms; Open repair; Asymptomatic

\section{Introduction}

Hepatic artery aneurysms (HAA) are rare. Eighty per cent of patients present acutely with aneurysm rupture, with an attended high mortality. Diagnosis is difficult and often delayed, owing to the non-specific symptoms and lack of clinical findings $[1,2]$. A review of the literature showed that the HAA had surpassed splenic artery aneurysm (SAA) as the most frequently reported visceral artery aneurysm [3]. This recent trend is thought to be due to the proliferation of centres performing invasive diagnostic and therapeutic hepatobiliary procedures, many of which have hepatic artery pseudo-aneurysm formation as a recognised complication [4]. The natural history of HAA is poorly understood, however, it is suggested that mortality following spontaneous rupture is as high as $40 \%$. Statistics such as these sanction an aggressive approach to the management of the HAA $[5,6]$.

\section{Case Report}

A 66-year-old man was admitted in our department with a hepatic artery aneurysm. The aneurysm was asymptomatic and was an incidental finding as a result of an abdominal ultrasound to investigate an episode of pain in the umbilical region. Comorbidities in our patient included hyperlipidaemia and hypertension. The patient had no history of abdominal trauma or invasive hepatobiliary procedures. A computed tomography angiography (CTA) was performed and revealed a $26 \mathrm{~mm}$ diameter saccular aneurysm in the common hepatic artery at the level of the origin of the gastroduodenal artery (Figure 1). An angiography of the celiac trunk was also performed for better anatomical characterization (Figure 2). Our initial plan was to perform a bypass from the splenic artery to the proper hepatic artery, but intraoperatively we verified that this segment was also aneurysmatic. The dissection of the aneurysm which, presented inflammatory characteristics, was very laborious and we did not identify any healthy segment of the proper hepatic artery. We performed ligation of the origin of the common hepatic artery and of the proper hepatic artery to exclude the aneurysm with subsequent interposition of reversed great saphenous vein graft between the splenic artery and the right hepatic artery.

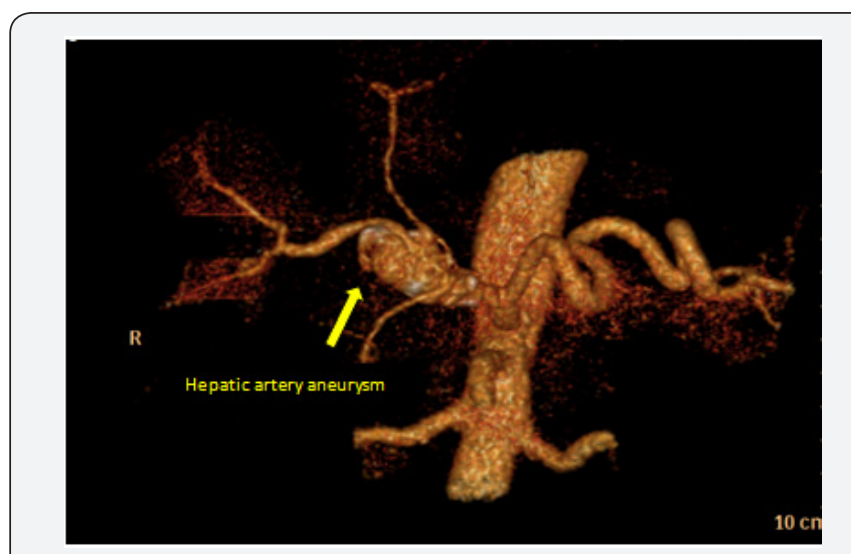

Figure 1: Preoperative computed tomography angiography. 


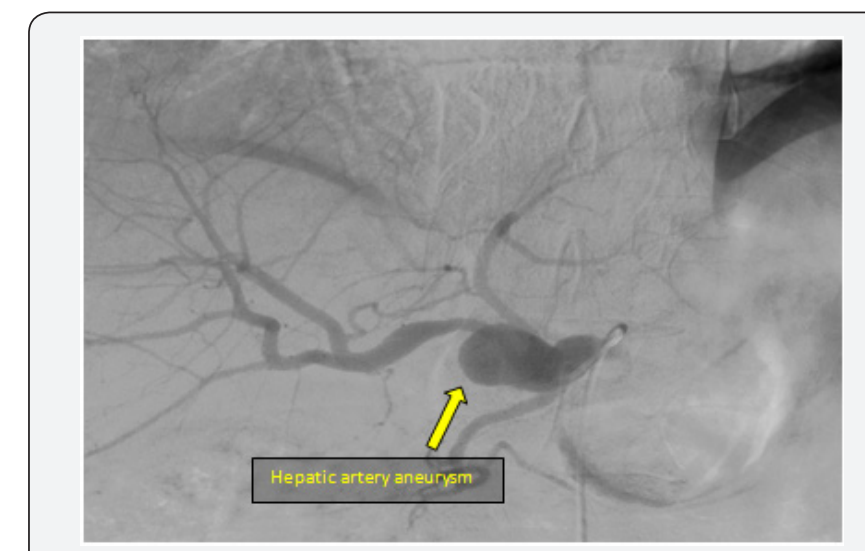

Figure 2: Celiac arteriography.

The gastroduodenal artery had a good backflow and we performed a bypass with saphenous vein between that artery and the left hepatic artery. We performed a biopsy of the wall aneurysm and sent to a microbiological and anatomopathological study. In the postoperative period we observe elevation of hepatic biomarkers (AST-486; ALT-166) related to liver ischemia and consequent cytolysis during surgery. An arterial duplex ultrasound was later performed which revealed bypass patency.

The biomarkers returned to normal baseline 3 days after the surgery. Microbiological study showed no bacterial growth and anatomopathological study was not conclusive. The patient had an uneventful postoperative recovery and was discharged 10 days later with indication to start Clopidogrel $75 \mathrm{mg}$ once a day for 6 months. One month after the surgery he underwent a computed tomography angiography (CTA) that revealed patency of the bypass (Figure 3).

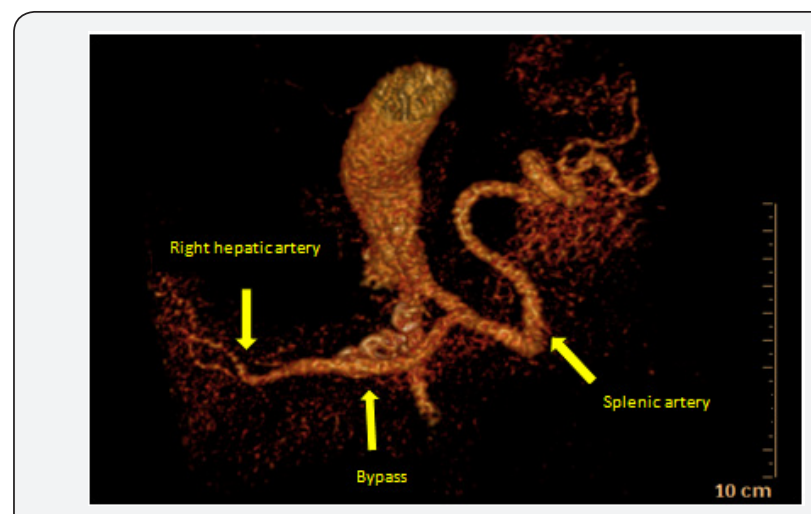

Figure 3: Follow-up CT (reconstruction) 1 month after surgery showed bypass patency between the splenic artery and the right hepatic artery and no liver infarction.

The Doppler ultrasound showed low arterial flow in the gastroduodenal- left hepatic artery bypass, it is probably for this reason that the bypass does not appear in the CTA. The follow-up will be performed every 3 months in the first year and thereafter every 6 months for 5 years with abdominal arterial duplex ultrasound to determine the bypass patency and definitive exclusion of the aneurysm. We use also hepatic biomarkers to assess postoperative hepatic function and progress.

\section{Discussion}

True HAAs represent about $20 \%$ of all visceral aneurysms. They are manifested most commonly in men and are mainly associated with arteriosclerotic disease, fibro muscular dysplasia, cystic medial necrosis, and portal hypertension [7]. Clinical presentation ranges from incidental detection of asymptomatic aneurysms on ultrasound or Computerised Tomography, to acute abdominal pain and cardiovascular collapse in the event of rupture, which carries mortality in the region of $40 \%$ [7]. The clinical diagnosis is difficult due to the paucity of symptoms prior to rupture. Classical triad of epigastric pain, haemobilia and jaundice, is rarely seen as $80 \%$ of patients present acutely following rupture of the aneurysm.

Unlike aortic aneurysms, the risk of rupture relative to size is unknown and the current advice is that all lesions warrant therapy. Some authors recommended that aneurysmal repair should be considered in HAA larger than $2 \mathrm{~cm}$. The factors which influence the endovascular management of extrahepatic aneurysms are the presentation of the patient, the site relative to the gastroduodenal artery and, most importantly, the morphology of the lesion. Potential endovascular options include embolization of the aneurysm, stenting of the aneurysm and embolization of the common hepatic artery.

In this case we chose not to place a covered stent because the artery was tortuous and because stent thrombosis could cause severe ischemia of the liver. Endovascular embolization without reconstruction has become the primary treatment for intrahepatic aneurysms or asymptomatic common HAAs. However, vascular reconstruction is required for the treatment of proper hepatic artery aneurysms to prevent hepatic ischemia resulting from interruption of collateral circulation through the gastroduodenal, pancreaticoduodenal arcade, and right gastric arteries $[8,9]$.

In our case the aneurysm involved de common hepatic artery and the origin of the gastroduodenal artery and embolization of hepatic artery at this level would deprive the liver of collateral gastroduodenal flow and theoretically increase the risk of hepatic necrosis. As we have described previously, aneurysm exclusion with saphenous vein graft between the splenic artery and the right hepatic artery was performed. To maintain perfusion of the left hepatic artery we opted to perform a bypass between the gastroduodenal artery and the left hepatic artery.

\section{Conclusion}

Elective open surgical repair of HAAs has been shown to be associated with high success rates and low complication rates. As this case demonstrates, surgery may be the most appropriate option in cases where the anatomical characteristics of the aneurysm preclude against endovascular repair. 


\section{References}

1. O’Driscoll D, Olliff SP, Olliff JFC (1999) Hepatic artery aneurysm. Br J Radiol 72(862): 1018-1025.

2. Harlaftis NN, Akin JG (1977) Hemobilia from ruptured hepatic artery aneurysm. American Journal of Surgery 133(2): 229-232.

3. Shanley CJ, Shah NL, Messina LM (1996) Common splanchnic artery aneurysms: splenic hepatica and celiac. Ann Vasc Surg 10(3): 315-322.

4. Jaunoo SS, Tang TY, Uzoigwe C (2009) Hepatic artery aneurysm repair: a case report. Journal of Medical Case Reports 3: 18.

5. Abbas MA, Fowl RJ, Stone WM (2003) Hepatic artery aneurysm: factors that predict complications. J Vasc Surg 38(1): 41-45.

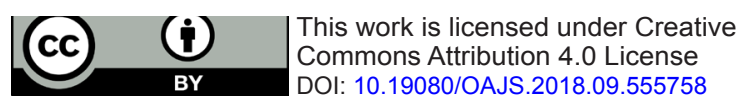

6. Michels NA (1966) Newer anatomy of the liver and its varient blood supply and collateral circulation. American Journal of Surgery 112: 337-347.

7. Pasha SF, Gloviczki P, Stanson AW (2007) Splanchnic artery aneurysms. Mayo Clin Proc 82(4): 472-479.

8. Messina LM, Shanley CJ (1977) Visceral artery aneurysms. Surg Clin North Am 77: 425-442.

9. Dougherty MJ, Gloviczki P, Cherry KJ (1993) Hepatic artery aneurysms: evaluation and current management. Int Angiol 12(2): 178-184.

\section{Your next submission with Juniper Publishers} will reach you the below assets

- Quality Editorial service

- Swift Peer Review

- Reprints availability

- E-prints Service

- Manuscript Podcast for convenient understanding

- Global attainment for your research

- Manuscript accessibility in different formats

( Pdf, E-pub, Full Text, Audio)

- Unceasing customer service

Track the below URL for one-step submission https://juniperpublishers.com/online-submission.php 